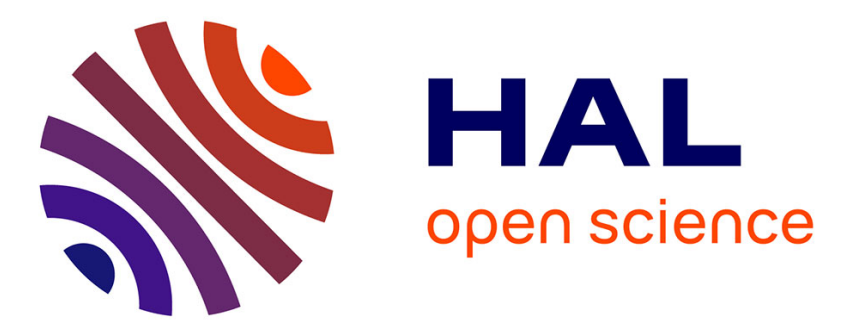

\title{
Status of the cryomodules for the SPIRAL 2 superconducting LINAC
}

P. Bosland, P.E. Bernaudin, G. Devanz, C.G Thomas-Madec, A. Perolat, H. Saugnac, G. Olry, G. Martinet, F. Lutton, S. Blivet, et al.

\section{- To cite this version:}

P. Bosland, P.E. Bernaudin, G. Devanz, C.G Thomas-Madec, A. Perolat, et al.. Status of the cryomodules for the SPIRAL 2 superconducting LINAC. 22nd Particle Accelerator Conference 07 (PAC'07), Jun 2007, Albuquerque, United States. pp.THOAKI04. in2p3-00169255

HAL Id: in2p3-00169255

https://hal.in2p3.fr/in2p3-00169255

Submitted on 3 Sep 2007

HAL is a multi-disciplinary open access archive for the deposit and dissemination of scientific research documents, whether they are published or not. The documents may come from teaching and research institutions in France or abroad, or from public or private research centers.
L'archive ouverte pluridisciplinaire HAL, est destinée au dépôt et à la diffusion de documents scientifiques de niveau recherche, publiés ou non, émanant des établissements d'enseignement et de recherche français ou étrangers, des laboratoires publics ou privés. 


\title{
STATUS OF THE CRYOMODULES FOR THE SPIRAL 2 SUPERCONDUCTING LINAC
}

\author{
P. Bosland, PE Bernaudin, G. Devanz, C. Thomas-Madec, A. Pérolat, CEA Saclay \\ H. Saugnac, G. Olry, G. Martinet, F. Lutton, S. Blivet, D. Longuevergne, IPN Orsay \\ Y. Gomez-Martinez, F. Vezzu, M Fruneau, LPSC Grenoble \\ T. Junquera, *R. Ferdinand, SPIRAL2/GANIL Caen
}

\begin{abstract}
The SPIRAL 2 superconducting LINAC is composed of 2 cryomodule families. The first family in the low energy section, called cryomodules $\mathrm{A}$, is composed of 12 cryomodules housing a single cavity at beta $=0.07$. The second family in the high energy section, called cryomodules $\mathrm{B}$, is composed of 7 cryomodules housing 2 cavities at beta $=0.12$. The frequency of these QWR resonators is $88.0525 \mathrm{MHz}$, and the design goal for the accelerating field $E_{a c c}$ is $6.5 \mathrm{MV} / \mathrm{m}$. This paper describes the present status of the cryomodules development, cavities and couplers results.
\end{abstract}

\section{INTRODUCTION}

The GANIL's SPIRAL 2 Project [1] aims at delivering high intensities of rare isotope beams by adopting the best production method for each respective radioactive beam. The unstable beams will be produced by the ISOL "Isotope Separation On-Line" method via a converter, or by direct irradiation of fissile material. On the basis of referee reports of international experts and committees, the positive evaluations by IN2P3/CNRS and DSM/CEA GANIL, and the support of the region of BasseNormandie, the French Minister of Research took the decision on the construction of SPIRAL 2 in May 2005.

The driver will accelerate protons $(0.15$ to $5 \mathrm{~mA}-$ $33 \mathrm{MeV})$, deuterons $(0.15$ to $5 \mathrm{~mA}-40 \mathrm{MeV})$ and heavy ions (up to $1 \mathrm{~mA}, \mathrm{Q} / \mathrm{A}=1 / 3 \quad 14.5 \mathrm{MeV} / \mathrm{u}$ to $1 / 6$ 8.5 MeV/A). It consists of high performance ECR sources, a RFQ, and the superconducting light/heavy ion linac. The driver is also asked to provide all the energies from $2 \mathrm{MeV} / \mathrm{u}$ to the maximum designed value.

The superconducting linac is composed of cryomodules A developed by CEA-Saclay, and cryomodules B developed by IPN-Orsay. Both types of cavities will be equipped with the same power coupler specified for a maximum power of $20 \mathrm{~kW}$, which is developed in a third laboratory, LPSC-Grenoble.

General development programs are quite similar for both cryomodules: a first qualification cryomodule under assembly will be tested before the series. These qualification cryomodules shall reach the specifications for the LINAC and will become the spare ones for the machine. All the components of the series (cavities and cryomodules) will be fabricated in industry. Cavities chemical treatments, HPR rinsing in clean room, assembly, and RF tests of the cavities in vertical cryostat and RF power tests of the cryomodules will be made in the respective labs.

In order to present comparable values of the 07 Accelerator Technology Main Systems accelerating field for the two cavity types at different $\beta$, $E_{a c c}$ is defined as $E_{a c c}=\operatorname{Vacc} /\left(\beta_{o p t} \lambda\right)$, where

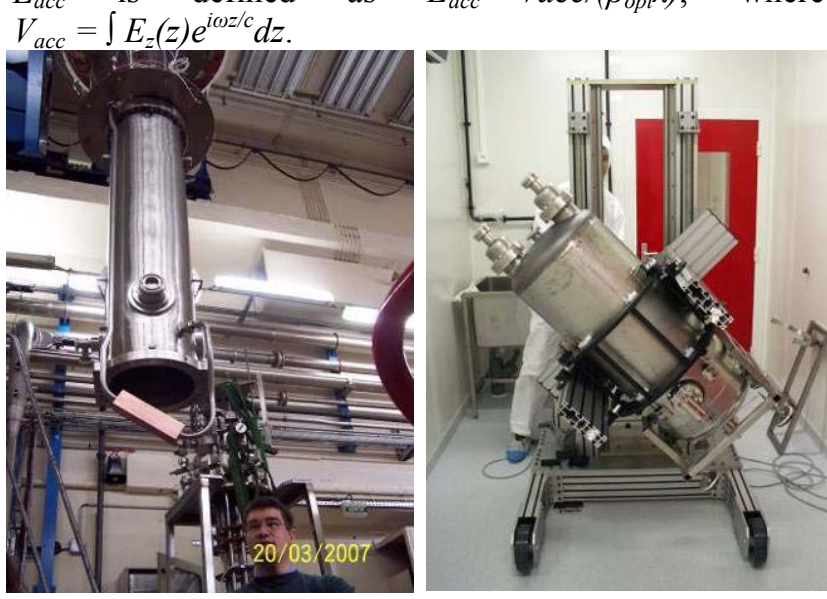

Figure 1: Cavity A and one of the 2 cavities B in the clean room with the handling robot

\section{CRYOMODULES A - $\boldsymbol{\beta}=\mathbf{0 . 0 7}$}

Details of the cavity and cryomodule design were described in $[2,3]$. We focus here on the general points and the status of the project.

The two main constraints for the cryomodule design were to shorten the cryomodule length and to isolate the cavity vacuum from the insulation vacuum. These two constraints lead to very compact cryomodules: each unit is $610 \mathrm{~mm}$ long and is separated from the next one by a $580 \mathrm{~mm}$ gap filled with a diagnostic box and two quadrupoles.

The cavity tuner works by cavity deformation perpendicularly to the beam axis. This design saves room in the beam axis direction. The cavity mechanical design was optimized in order to reach a full tuning range of $\pm 25 \mathrm{kHz}$ at $4 \mathrm{~K}$, without plastic deformation of the niobium cavity.

The experimental results of the external pressure variation on the cavity frequency $(3.35 \mathrm{~Hz} / \mathrm{mbar})$ confirmed the calculated value of $3.4 \mathrm{~Hz} / \mathrm{mbar}$. This sensitivity to pressure variation will allow \pm 3 mbar variation on the liquid helium bath in order to keep frequency shifts within $1 / 10^{\text {th }}$ of the $133 \mathrm{~Hz}$ bandwidth $\left(Q_{\text {ext }}=6.610^{5}\right)$. However frequency shifts are also generated by the mechanical vibrations of the cavities. A damping system based on the Legnaro type [4] is in development in order to limit this effect.

Each cavity A will be supplied by a $10 \mathrm{~kW} \mathrm{RF}$ power amplifier. The first cavities of this low beta section working at low accelerating field $(\approx 0.49 \mathrm{MV} / \mathrm{m}, 0.5 \mathrm{~kW})$ 
will require less power than the last cavities of the section $(\mathrm{P} \approx 6.8 \mathrm{~kW})$, working at about $\mathrm{E}_{\mathrm{acc}}=5 \mathrm{MV} / \mathrm{m}$.

The program for the manufacturing, the assembly and the tests of the 13 cryomodules is scheduled over 4 years between 2007 and 2010.

At present, a first prototype cavity has been tested [2]; all components for the qualification cryomodule, including the second qualification cavity, are fabricated and the RF tests of the cavity in vertical cryostat will be performed during summer at Saclay. Then, the cavity will be mounted in the cryomodule. However, because of the small size of our clean room at Saclay, the clean assembly shall be made in two phases. At first the HPR will be performed at Saclay and all components will be prepared for clean assembly. Secondly, the cavity and associated components, will be mounted in the vacuum tank in the large clean room at CERN. At last, the partially assembled cryomodule will return to Saclay for final assembly in our clean workshop.

Modifications of a test stand on the SupraTech Cryo/RF area of the Saclay site are in progress in order to perform $\mathrm{RF}$ power tests at $88 \mathrm{MHz}$. In October 2007, low RF power testsof the cryomodule with a critically coupled antenna $(\beta=1)$ are scheduled. The main purpose of the low $\mathrm{RF}$ power tests is to measure the $\mathrm{Q}$ vs. $\mathrm{E}_{\text {acc }}$ curve, the cryogenic losses and to analyse the mechanical vibrations and the possible effects of a pollution originating from the neighbouring diagnostics boxes. Then the qualification cryomodule will be dismounted and remounted with the power coupler and RF power tests with the cryomodule in the accelerator configuration will be performed. These RF power tests are foreseen at the beginning of year 2008.

The order of the cavities for the series will be placed before the end of September 2007 and that of the cryomodules components before the end of December 2007. The test of the last cryomodule A is scheduled in November 2010.
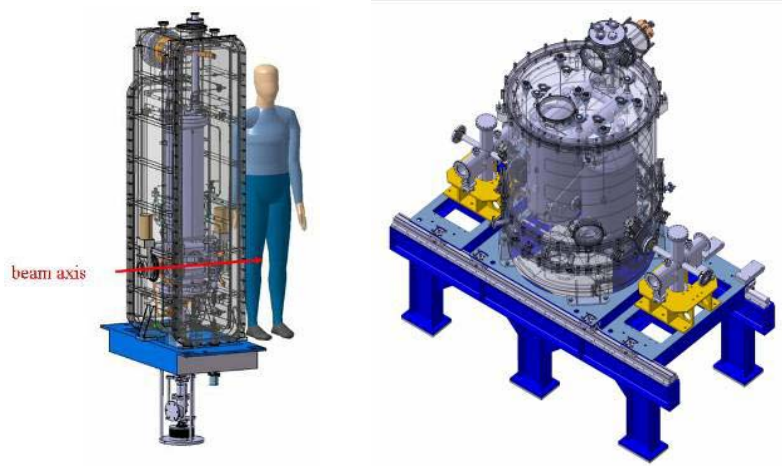

Figure 2: One the 12 cryomodules $\mathrm{A}$ and 1 of the 7 cryomodules B.

\section{CRYOMODULES B $-\boldsymbol{\beta}=\mathbf{0 . 1 2}$}

\section{Resonators}

At present time, one prototype cavity has been tested, two resonators, part of the qualification cryomodule, have been manufactured. The first qualification resonator equipped with its Titanium helium tank has been tested in vertical cryostat in May 2007, the second one is planed to be tested at the end of June 2007.

The first cavity of the 16 cavities serial production, ordered to the ACCEL Company, is planed to be delivered in March 2008.

The first qualification cavity, as described on Figure 3, shows good electro-magnetic performances $\left(\mathrm{E}_{\mathrm{s}} / \mathrm{E}_{\mathrm{acc}}=\right.$ $\left.4.76 \& \mathrm{~B}_{\mathrm{s}} / \mathrm{E}_{\mathrm{acc}}=9.35 \mathrm{mT} / \mathrm{MV} / \mathrm{m}, \quad \mathrm{L}_{\mathrm{acc}}=0.41 \mathrm{~m}=\beta \times \lambda\right)$. Despite modification of the electric field area shape, multipacting barriers, identical to the ones observed on the prototype, were measured. One barrier (around $1.3 \mathrm{MV} / \mathrm{m}$ ) can be easily processed while two or more barriers at very low field (between 30 and $80 \mathrm{kV} / \mathrm{m}$ ) cannot. These barriers were observed at the same fields on the 2 cavity types.

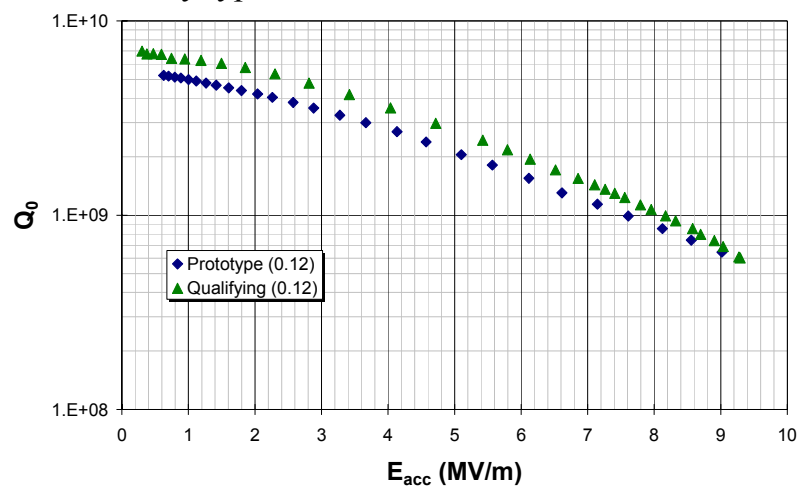

Figure 3: Q curve of the first qualification cavity B at $4.2 \mathrm{~K}$

The mechanical design was modified compared to the first prototype with the aim to reduce the frequency shift due to helium pressure fluctuations. The stability at $4.2 \mathrm{~K}$ is around $6 \mathrm{~Hz} / \mathrm{mbar}$ (confirmed at $300 \mathrm{~K}$ on the second qualification cavity) which is better than it was measured to $18 \mathrm{~Hz} / \mathrm{mbar}$ on the prototype.

The tuning procedure during manufacturing was validated. On each qualification cavity welding in different ways the helium vessel were performed in order to compare frequency shifts and mechanical deformation on the cavity parts. The target frequency will be defined after fabrication taking into account the frequency shift resulting from the chemical polishing and the cooling of the second qualification cavity.

\section{Cold Tuning}

The cavity tuning after manufacturing will be performed using superconducting plungers inserted on the top of the cavity inside the magnetic volume. After several successful tests with fixed plungers [5], a test with a movable plunger was performed on the prototype cavity in February 2007. A $30 \mathrm{~mm}$ diameter plunger displacement within $4 \mathrm{~mm}$ range allows a dynamic tuning of $4 \mathrm{kHz}$. The plunger displacements didn't induce perturbation on the resonator performances $\left(\mathrm{E}_{\mathrm{acc}} \approx 7.5 \mathrm{MV} / \mathrm{m}, \mathrm{Q}_{0}>3.010^{9}\right)$. Two systems are being manufactured for the qualification cryomodule. The 
theoretical resolution is $1 \mathrm{~Hz}$ and the tuning speed is above $1000 \mathrm{~Hz} / \mathrm{min}$ (The specified pressure stability for the cryoplant leads to a frequency stability of around $60 \mathrm{~Hz} / \mathrm{min}$ for the beta 0.12 cavities). The plunger will be driven using a warm stepping motor (200 steps/turn and 1:25 reduction ratio) installed outside the cryostat. Tests on long term operation and life time evaluation of the system are planed during the qualification cryomodule experiments.

\section{Cryostat}

The height of the cryomodule dimensions (from the power coupler RF connector to the cryogenic connection flange) is about $3 \mathrm{~m}$, and the axial dimension (between the two extremities warm beam valves) is $1.3 \mathrm{~m}$. The qualification cryomodule is under assembly, and will be tested in late August. One cavity will be mounted with an antenna at the critical coupling $(\beta=1)$ and one with a power coupler.

\section{COUPLERS}

The RF couplers have to provide $12 \mathrm{~kW} \mathrm{CW}$ power to the cavities at $88.05 \mathrm{MHz}$ for the design goal accelerating field of $6.5 \mathrm{MV} / \mathrm{m}[6]$.

The coupler has a fixed coaxial antenna with a discshape ceramic (6 mm thickness). The coupling will be fixed, and the RF system will have to manage some reflected power. The coupler is standing upright at the bottom of each cavity. Simulation taking into account the copper coating conductivity variation with temperature estimate a $1 \mathrm{~W}$ deposited power on the cavities bottom. Tests were made on the cavity B showed that up to $15 \mathrm{~W}$ can be deposited without perturbation of the cavity performances.

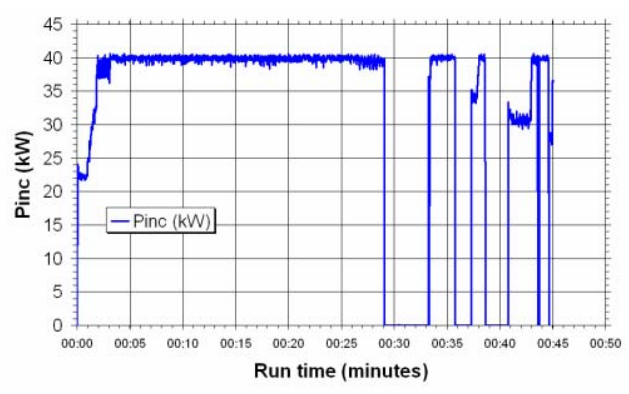

Figure 4: Couplers commissioning.

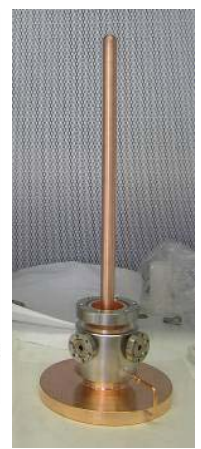

Two coupler prototypes have been tested (head to head) up to $40 \mathrm{~kW} \mathrm{CW}$ with good results (Figure 4). The reflection coefficient $\left(\mathrm{S}_{11}\right)$ measured was less than $-30 \mathrm{~dB}$ and only some increase in the electron current on the pickup probe has been observed in the $0-300 \mathrm{~W}$ range and not for higher power. Analytical studies have shown that multipactor may occur mainly at low power, below $100 \mathrm{~W}$.

The conditioning of three qualification couplers is in progress. These couplers are going to be mounted on the cavities and in September 2007. The use of the coupler in superconducting cavities requires very clean surfaces. Therefore a clean room has been constructed housing high purity water cleaning system. The test bench is inside this clean room to keep the couplers in the best conditions of cleanness. They will be shipped to the cryomodule groups under vacuum.

The goal is to start the production of 33 couplers at the end of the year; the completion of this production is foreseen in 2010.

\section{FUTURE PLAN}

The different teams of each laboratory involved in this project are now preparing the qualification cryomodules of both types, A and B, in order to begin the RF tests in August 2007. Several series of RF tests will be performed with different cryomodules configurations until February 2008. The order of the cavities A should be placed in September 2007. The contract for cavities B was signed in February 2007 with ACCEL company production will begin in September 2007. The order of the cryomodules components for both series A and B are foreseen before the end of 2007. The RF test of the last cryomodule is scheduled at the end of 2010 .

Installation in the linac tunnel is foreseen in 2011.

\section{REFERENCES}

[1] T. Junquera, P. Bertrand, R. Ferdinand, M. Jacquemet, "The high intensity superconducting Linac for the SPIRAL 2 project at GANIL", proc LINAC 2006, Knoxville, USA, p 142-144

[2] P-E. Bernaudin, P. Bosland, S. Chel, P. de Girolamo, G. Devanz, P. Hardy, F. Michel, "Design of the LowBeta, Quater-Wave Resonnator and its Cryomodule for the SPIRAL2 Project', EPAC'06, Lucerne, July 2004, p.1276.

[3] G. Devanz, "SPIRAL2 Resonators", 12th SRF Workshop 2005, Cornell University, July 2005, $\mathrm{MoPO} 2$.

[4] A. Facco, "Mechanical stabilisation of superconducting quater wave resonators", Proc. of the 1997 PAC 97, Vancouver, Canada, pp.30843086.

[5] G. Olry, J-L. Biarrotte, S. Blivet, S. Bousson, C. Commeaux, C. Joly, T. Junquera, J. Lesrel, E. Roy, H. Saugnac, P.Szott, "Development of a beta 0.12, $88 \mathrm{MHz}$, quarter wave resonator and its cryomodule for the spiral2 project", 12th SRF Workshop 2005, Cornell University, July 2005, TuP37.

[6] Y. Gómez Martínez et al, "theorical study and experimental result of the RF coupler prototypes of Spiral2", EPAC 06, Edinburgh, June 2006, THPCH160 